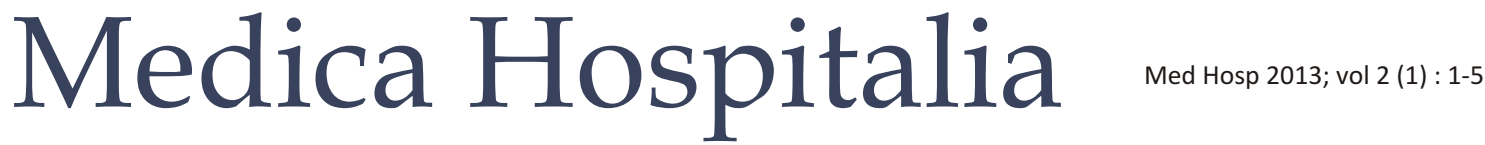

Review Article

Medical Progress

\section{Prediksi Keberhasilan Kehamilan Teknik Fertilisasi in Vitro Pada Berbagai Umur Istri}

\author{
Soegiharto Soebijanto \\ Departemen Obstetri dan Ginekologi, Divisi Endokrinologi Reproduksi \\ Fakultas Kedokteran Universitas Indonesia/RSUPN Dr. Cipto Mangunkusumo Jakarta
}

\begin{abstract}
Abstrak
Obyektif: Tulisan ini mempelajari hubungan keberhasilan kehamilan teknik fertilisasi in vitro dengan umur istri.

Metode: Dilakukan penilaian kehamilan pada 8 buah pusat pelayanan fertilisasi in vitro di Indonesia: di Rumah Sakit Anak dan Bersalin Harapan Kita sejak tahun 1997 sampai 2001 dan 7 Pusat Pelayanan fertilisasi in vitro di Indonesia. Induksi folikel dilakukan dengan long protocol, short protocol dan natural cycle. Inseminasi dilakukan dengan cara inseminasi di cawan petri dan dengan cara ICSI (intra cytoplasmic sperm injection). Pengambilan spermatozoa dilakukan dengan masturbasi, biopsi testes, dan biopsi epididimis. Keberhasilan kehamilan dinilai dengan kehamilan kimiawi, adanya denyut jantung bayi dan kelahiran bayi hidup (take home baby).

Hasil: Diperoleh hasil kehamilan 34\% untuk kelompok umur di bawah 30 tahun, 33,75\% untuk kelompok umur 31-35 tahun, 26\% untuk kelompok umur 36-40 tahun dan $8 \%$ untuk kelompok umur di atas 40 tahun.
\end{abstract}

Kata kunci: fertilisasi in vitro, umur istri

\section{Predictor of succesful pregnancy rate with in vitro fertilization techniques in relation with age of the woman}

\begin{abstract}
Objective: This study is to determine the relationship between successful pregnancy rate with in vitro fertilization techniques and the age of the woman.

Methods: Pregnancy assessment in 8 cases in-vitro fertilization center in Indonesia: The Children's Hospital and Maternity Harapan Kita from 1997 to 2001 and 7 in IVP centers in Indonesia. Ovulation induction was done with a long follicular protocol, short protocol and the natural cycle. Insemination technique was done both by petri dish insemination and an ICSI (intra-cytoplasmic sperm injection) technique. Sperm retrieval was done by masturbation, biopsy of testes and epididymis. The success of pregnancy was assessed through laboratory examination on the time of pregnancy, the fetal heart rate and the presence of live births (take home baby).

Results: The succesful pregnancy was at $34 \%$ for the age group below 30 years, $33.75 \%$ for the age group $31-35$ years, $26 \%$ for the age group $36-40$ years and $8 \%$ for the age group above 40 years.
\end{abstract}

Keywords: In-vitro fertilization, the age of the woman.

\section{PENDAHULUAN}

Infertilitas adalah ketidak mampuan pasangan untuk menghasilkan anak setelah menikah dan melakukan sanggama teratur tanpa memakai kontrasepsi. Sesuai dari penyebab infertilitas ada beberapa pilihan cara pengobatan yang berkaitan dengan kemungkinan mendapatkan kehamilan. Pada penyebab yang ringan terapi dapat dilakukan dengan teknik yang sederhana, akan tetapi pada penyebab yang berat harus dengan teknik yang kompleks dan mahal dengan persiapan khusus (fertilisasi in vitro $=$ teknik reproduksi berbantu $=$ TRB). TRB akan membantu mewujudkan keinginan mendapatkan kehamilan pada istri dengan kelainan yang berat, meskipun harus melalui seleksi dan persiapan yang teliti dan cukup panjang. ${ }^{1}$

Untuk mempersiapkan pasien yang akan mengikuti program TRB dilakukan beberapa 
pemeriksaan antara lain: lama perkawinan, penyebab gangguan fertilitas, pemeriksaan dan pengobatan yang pernah dilakukan, upaya untuk mendapatkan kehamilan sebelumnya, dan yang tak kalah penting adalah umur istri. ${ }^{2}$ Oleh karena informasi mengenai TRB belum merata ke seluruh masyarakat, banyak pasutri yang datang ke klinik reproduksi yang terpadu sudah terlambat, sehingga usia istri sudah cukup lanjut.

Umur ideal untuk hamil adalah antara 20-30 tahun. Percepatan penurunan kemampuan hamil akan terjadi mulai umur 35 tahun. Untuk wanita dengan umur 40 tahun atau lebih kemungkinan untuk hamil menurun $50 \%$ pada setiap penambahan umur dan saat umur mencapai 45 tahun kesempatan itu adalah nol. ${ }^{3}$

Semua ini penyebabnya adalah faktor oosit. Pada umur lanjut akan terjadi kesalahan meiosis yang akan menghasilkan oosit yang abnormal. Jumlah oosit yang didapat akan sedikit, kualitas oosit menurun, angka fertilisasi dan jumlah embrio akan sedikit. ${ }^{3,4}$ Banyak penelitian menemukan bahwa umur 40 tahun merupakan batas maksimal untuk layak dilakukan prosedur TRB. ${ }^{5,6}$ Batas umur ini memiliki keberhasilan kehamilan dengan program donor sperma dan kemungkinan untuk mendapatkan kehamilan spontan..$^{6-8}$ Analisis dengan regresi multipel dari faktorfaktor yang berperan diperoleh hasil angka keberhasilan melahirkan hidup $17 \%$ per siklus pada umur 30 tahun, menurun menjadi $7 \%$ pada umur 40 tahun dan $2 \%$ pada umur 45 tahun. ${ }^{9}$ Meskipun umur merupakan prediktor penting namun umur kronologis merupakan prediktor yang buruk terhadap ketuaan ovarium. ${ }^{10}$ Pada penelitian wanita yang mengalami respon buruk pada stimulasi, ternyata jumlah folikel antral yang diperiksa dengan USG lebih rendah dibanding kontrol. ${ }^{11}$

\section{METODE}

Data penelitian diambil dari data, 1987 sampai 2007 di Rumah Sakit Anak dan Bersalin Harapan Kita, Klinik Yasmin FKUI/RSCM tahun 2006 sampai 2008 dan 6 Pusat pelayanan fertilissai in vitro lainnya (Aster, RS Hasan Sadikin, Bandung; Halim Fertility Center, Medan; Morula, RS Bunda, Jakarta; Teratai, RS Gading Pluit Jakarta, Family, RS Family Pluit Jakarta Barat; Graha Amerta, RS Sardjito Yogyakarta) di Indonesia dari tahun 2007 sampai 2008.

Metode yang digunakan adalah pengambilan data retrospektif. Metode kajian pustaka adalah metode yang digunakan dengan cara mengambil data-data dari buku dan internet.

Hasil penelitian disajikan dalam bentuk tabel induk dan dihitung persentasenya. Syarat mengikuti program TRB adalah: 1) telah melakukan pemeriksaan dasar infertilitas, 2) telah mengikuti penjelasan secara rinci tentang tindakan dan terapi pada TRB, 3) dapat memahami serta menyetujuinya, 4) mampu membiayai proses TRB. Indikasi: 1) tersumbat kedua saluran telur, 2) oligospermia berat, 3) unexplain infertility, 4) endometriosis stadium III/ IV (AFS), 5) penanganan konvensional sebelumnya gagal.

Pada haid hari ke-2 dilakukan pemeriksaan dengan ultrasonografi transvaginal untuk menilai keadaan rahim (mengukur panjang, lebar, dan tebal), serta melihat apakah ada tumor jinak (miom). Bila ada maka ditentukan berapa jumlah dan ukuran juga letaknya, dan melihat jumlah indung telur dan ukurannya serta menghitung jumlah folikel basal (basal anthral folikel) dan mengelompokkan berdasarkan atas jumlah folikel basal menjadi: hipo-responder apabila jumlahnya kurang dari 5 buah, normo-responder apabila jumlahnya antara 5-15 buah, dan hiper-responder apabila jumlahnya lebih dari 15 buah. Jumlah folikel basal merupakan gambaran ovarian reserve (cadangan folikel basal) yang berguna sebagai prediksi tingkat kesuburan wanita. Pemeriksaan berikutnya mengambil sampel darah untuk melihat konsentrasi hormon dasar (basic profile hormone) yang meliputi FSH (Folicel Stimulating Hormone), LH (Luteinizing Hormone), PRL (Prolactin), dan E2 (Estradiol).

Haid hari ke-8 sampai dengan 12 melakukan pemeriksaan HSG (Hystero Salphingo Graphy) untuk menilai keadaan rongga rahim dan kedua saluran telur. Haid hari ke-18 sampai dengan 20 melakukan uji pemindahan embrio menggunakan kateter Frydman (kateter yang akan dipakai untuk memindahkan embrio sesungguhnya) dan menilai kedalaman rongga rahim serta arah masuknya kateter ke dalam rahim.

Melakukan sperma analisis minimal 2 kali untuk mengetahui kualitas sperma sekaligus fluktuasinya. Pemeriksaan dilakukan dengan interval waktu 3-5 hari setelah sperma dikeluarkan kemudian dikeluarkan lagi di laboratorium untuk dilakukan analisa secara lengkap.

Adapun metode pengobatan yang dipakai dibagi menjadi tiga kelompok disesuaikan dengan kondisi pasutri yaitu:

Kelompok Long Protocol, pengobatan dimulai dengan pemberian Buserelin dimulai hari ke 21 terus menerus selama 2 minggu. Seterusnya diperiksa USG dan dilihat hormon dasarnya. Bila sudah memenuhi syarat selanjutnya Buserelin dilanjutkan dan ditambah dengan pemberian suntikan hormon yang berisi FSH rekombinan dengan dosis yang disesuaikan dengan respon pasien. Pasien diminta datang sehari dua kali: pagi jam 08.00 untuk USG guna memonitor perkembangan folikel dan pengambilan darah untuk menentukan konsentrasi hormon Estradiol. Siang harinya jam 13.00 disuntik hormon FSH rekombinan dengan dosis yang disesuaikan dengan perkembangan folikel dan konsentrasi hormon Estradiol sampai diameter folikel rata-rata $20 \mathrm{~mm}$ dan konsentrasi hormon Estradiol rata-rata $200 \mathrm{pg} / \mathrm{ml}$. Buserelin kemudian 
dihentikan dan diminta datang malam hari kira-kira jam 20.00 untuk diberikan suntikan hCG $10.000 \mathrm{IU} /$ intra muskuler guna pematangan sel telur.

Untuk selanjutnya 34 jam kemudian dilakukan OPU (ovum pick up) dengan menggunakan USG. Satu jam kemudian, suami mengeluarkan sperma untuk kemudian dicuci dengan cairan medium. Bagi yang tidak ada sel spermatozoanya pada ejakulat, sperma dapat dicari di testis atau di epididimis. Dari sanalah akan di dapat spermatozoa yang morfologinya baik untuk kemudian diinseminasikan dengan sel telur.

Inseminasi untuk pasangan yang suaminya bersperma bermutu baik (>20 juta/ml) 1 sel telur dicampur dengan 100.000 sel spermatozoa didalam cawan petri. Sedangkan yang bersperma kurang atau sperma dicari di testis atau epididmis selanjutnya diteruskan dengan teknik. Setelah itu, dimasukkan ke dalam inkubator untuk waktu 2-5 hari. Kemudian, dipilih hasil konsepsi yang berkwalitas baik dalam bentuk (morfologi) dan pembelahannya. Hanya yang memenuhi syarat saja dilakukan pemindahan atau tandur alih embrio ke dalam rongga rahim.

Selanjutnya setiap 4 hari sekali mendapatkan suntikan penguat (luteal face suport) dengan hCG 1500 IU/IM sebanyak 2 kali pemberian. Kemudian dilakukan pemeriksaan hormon Estradiol dan Progesteron sebagai monitor apakah embrio yang dimasukkan berkembang atau tidak. Kepastian kehamilan diperiksa pada hari ke-14 setelah tandur alih embrio dengan memeriksa air seni pagi hari, bila tesnya positif maka pasien tersebut dinyatakan hamil secara biokimiawi. Kehamilan klinis baru ditegakkan setelah 2 minggu kemudian akan terlihat dengan USG berupa kantong janin dengan fetal pole (calon janin) di dalamnya. Empat minggu kemudian, akan terlihat gambaran janin yang lengkap secara morfologi yang ditandai dengan adanya denyutjantung janin.

\section{Short Protocol}

Metode pengobatan ini memerlukan waktu sesuai dengan siklus haid \pm 28 hari. Pada dasarnya metode short protocol hampir sama dengan long protocol, perbedaannya terletak pada pemberian obat pemicu pematangan folikel
(FSH), yang diberikan mulai haid hari ke 2 dengan injeksi subkutan di daerah perut dengan dosis disesuaikan dengan kondisi pasien tiap hari, ditambah dengan pemberian $\mathrm{GnRH}$ antagonis 0,25 mg/subkutan mulai hari ke 7 selama 5 hari sampai diameter folikel rata-rata mencapai $18 \mathrm{~mm}$.

\section{Natural Protocol}

Metode pengobatan ini mengikuti pola haid istri dengan panjang siklus antara 21-28 hari. Mulai hari ke 2, dilakukan evaluasi genitalia interna dan konsentrasi hormon basal (FSH, LH, E2, PRL), untuk selanjutnya pada hari ke-6, 9, dan 11 dilakukan pemeriksaan konsentrasi hormon E2 dan dilihat diameter folikel ratarata, apabila sudah mencapai $14 \mathrm{~mm}$ dan konsentrasi E2 rata-rata lebih dari $100 \mathrm{pg} / \mathrm{ml}$, maka suntikan hCG diberikan 34 jam sebelum pengambilan telur.

\section{HASIL}

Pada Tabel 1 tampak hasil di RSAB Harapan Kita periode 1987-2001, pada kelompok usia kurang dari 30 tahun didapatkan 460 siklus yang telah dilakukan transfer embrio dan didapatkan kehamilan klinis sebanyak 137 pasutri atau 33\%. Pada kelompok usia 31-35 tahun terdapat 1012 siklus berhasil dilakukan transfer embrio pada $855(84 \%)$. Sementara itu yang telah dinyatakan hamil sebanyak 254 siklus atau 30\%. Pada kelompok usia 36-40 tahun terdapat 981 siklus, 6\% batal dilanjutkan sampai OPU, 695 (77\%) dilakukan tranfer embrio dan 148 (19\%) hamil. Dari kelompok umur di atas 40 tahun terdapat 145 siklus, 25 siklus batal, 85 transfer embrio dan 7 hamil.

Dari sini tampak bahwa umur terbanyak yang mengikutri program TRB adalah antara 31-40 tahun. Hal ini disebabkan pada kelompok dibawah 30 tahun, merupakan kelompok yang baru menikah sudah barang tentu penanganan dilakukan teknik yang lebih sederhana. Setelah gagal sudah jatuh pada umur 31-40 baru datang ke pelayanan TRB.

Pembatalan program $2 \%$ terjadi pada kelompok umur dibawah 30 tahun, $4 \%$ pada kelompok umur 31-35 tahun, 6\% pada kelompok umur 36-40 tahun dan

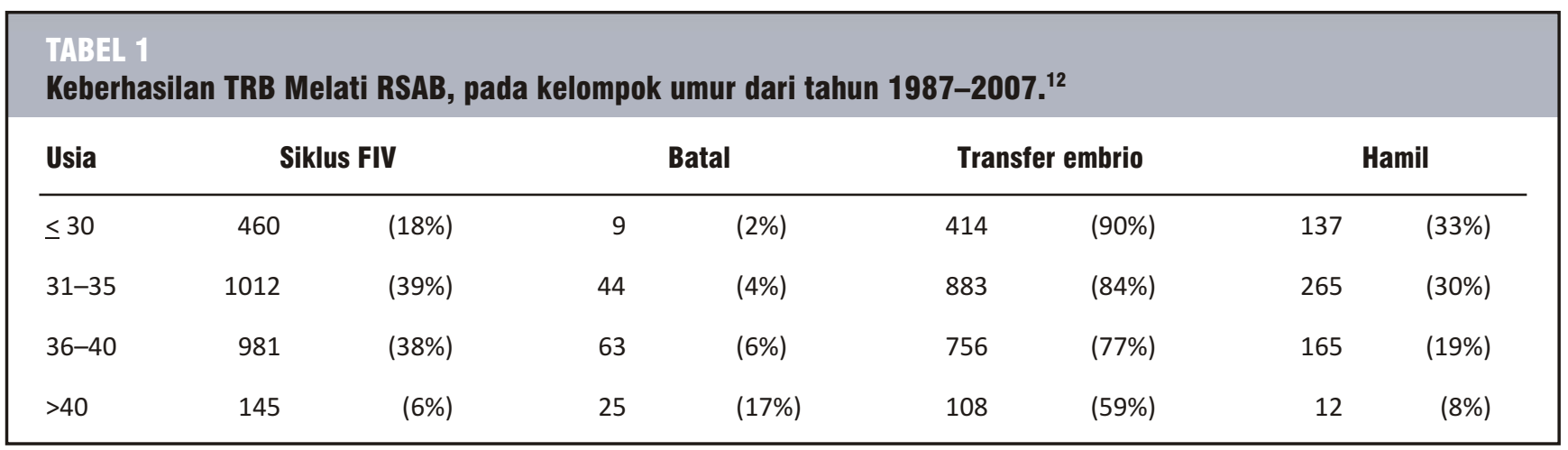


17\% dari kelompok umur diatas 40 tahun. Jadi jelas bahwa makin tinggi umur istri makin meningkat siklus yang dibatalkan karena tidak layak diteruskan disebabkan respon yang tidak baik terhadap stimulasi ovarium.

Ditinjau dari segi transfer embrio terdapat 90\% siklus ditransfer pada kelompok umur dibawah 30 tahun, $84 \%$ siklus ditransfer pada kelompok 31-35 tahun, 77\% siklus dilakukan embrio transfer pada kelompok umur 36-40 tahun dan 59\% embrio transfer dilakukan pada kelompok umur di atas 40 tahun. Dengan demikian jelas bahwa semakin tua umur istri semakin tinggi angka pembatalan embrio transfer, disebabkan mutu embrio yang tidak layak ditransfer. Hal ini disebabkan mutu oosit yang tidak baik karena adanya faktor penuaan oosit yang tinggal di ovarium.

\section{Hasil dari Klinik Yasmin 2004-2008}

Dipandang dari jumlah oosit diperoleh rata-rata 8,4 buah pada kelompok umur 20-25 tahun, 9,7 oosit pada

\begin{tabular}{|lcccccc|}
\hline $\begin{array}{l}\text { TABEL 2 } \\
\text { Jumlah pasien, 0osit dan kehamilan } \\
\text { menurut umur Pasien IVF di Pusat TRB Yasmin } \\
\mathbf{2 0 0 6 - 2 0 0 8}\end{array}$ \\
$\begin{array}{l}\text { Usia } \\
\text { (tahun) }\end{array}$ & $\mathbf{2 0 - 2 5}$ & $\mathbf{2 6 - 3 0}$ & $\mathbf{3 1 - 3 5}$ & $\mathbf{3 6 - 4 0}$ & $\mathbf{> 4 0}$ \\
\hline Pasien & 9 & 20 & 61 & 53 & 18 \\
$\begin{array}{l}\text { Oosit } \\
\text { Rata-rata }\end{array}$ & $\mathbf{7 6}$ & 194 & 476 & 270 & 74 \\
Oosit & 9,7 & 7,2 & 5 & 4 \\
Embrio & $\mathbf{5 1}$ & 94 & 258 & 139 & 41 \\
$\begin{array}{l}\text { Rata-rata } \\
\text { Embrio }\end{array}$ & $\mathbf{6}$ & 5 & 4 & 3 & 2 \\
Hamil & $\mathbf{3}$ & 8 & 17 & 13 & 1 \\
\% Hamil & $\mathbf{3 0}$ & 40 & 27,8 & 24,6 & 5,5 \\
\hline
\end{tabular}

\section{TABEL 3}

Jumlah siklus dan persentase kehamilan di 6 pusat TRB di Indonesia

Kehamilan pada kelompok umur

\begin{tabular}{lcccccc}
$\begin{array}{l}\text { Pusat } \\
\text { TRB }\end{array}$ & Siklus & $<35$ & $\mathbf{3 5 - 3 7}$ & $\mathbf{3 8 - 4 0}$ & $\mathbf{4 1 - 4 2}$ & $\mathbf{4 3 - 4 5}$ \\
\hline $\begin{array}{l}\text { P Pus } \\
\text { TRB }\end{array}$ & 708 & 38 & 38 & 28 & 20 & 6 \\
\end{tabular}

kelompok 26-30, 7,2 buah pada kelompok umur 31-35, 5 buah pada kelompok $36-40$ dan 4 buah pada kelompok umur di atas 40 tahun. Hal ini membuktikan bahwa terjadi penuaan ovarium walaupun dilakukan stimulasi sesuai standard, diperoleh jumlah yang semakin sedikit semakin umur wanita menua.

Hal ini sesuai dengan jumlah embrio yang diperoleh rata-rata semakin sedikit pada mereka yang lebih tua: 6 pada kelompok umur 25-30, 5 pada kelompok 26-30, 4 pada kelompok 31-35, 3 pada kelompok umur 36-40 dan 2 buah pada kelompok umur di atas 40 tahun. Angka kehamilan juga menurun sesuai dengan meningkatnya umur wanita, menurun drastis pada kelompok di atas 40 tahun.

Dengan demikian umur merupakan salah satu pertimbangan apakah pada kelompok ini masih akan ditangani dengan yang mahal ini, mengingat angka kehamilannya hanya 5,5\%. Sudah barang tentu perlu dicari parameter lain untuk menyaring apakah masih layak ditolong fertilitasnya misalnya parameter hormon.

\section{Hasil dari 6 pusat TRB di Indonesia yang lain}

Dari Tabel 3 tampak hasil dari 8 pusat pelayanan TRB di Indonesia. Berbeda dengan hasil Yasmin dan RSAB Harapan Kita disini ditemukan hasil yang sama bahwa keberhasilan kehamilan menurun sesuai dengan peningkatan umur istri. Terlihat terjadinya penurunan drastis kehamilan pada kelompok usia 38-40 tahun. Akan tetapi tidak terlalu berbeda dengan hasil yang diperoleh pada kelompok umur 41-42 tahun. Hal ini berbeda dengan hasil dari Klinik Yasmin dan RSAB Harapan Kita. Jadi faktor umur istri tidak dapat dijadikan patokan satu-satunya untuk penanganan infertilitas sebuah pasangan. Perlu dicari faktor lain yang akan memastikan apakah penanganan masih layak dilakukan.

\section{PEMBAHASAN}

Seperti telah diketahui sebelumnya bahwa dari berbagai penelitian terhadap tingkat kesuburan wanita, ternyata dipengaruhi oleh banyak faktor salah satu di antaranya adalah umur istri. Indung telur merupakan salah satu organ tubuh manusia yang mempunyai fungsi ganda yaitu sebagai organ reproduksi yang menghasilkan sel telur dan fungsi hormonal yang disamping berfungsi dalam reproduksi juga berfungsi dalam mempertahankan fungsi kewanitaan. Kedua fungsi tersebut tidak bertahan selama hidup tetapi mempunyai masa kerja yang terbatas dan tidak dapat diperpanjang lagi. Penuaan usia indung telur akan berjalan lebih cepat dibandingkan dengan kondisi fisik secara umum.

Dari pengamatan terhadap hasil yang diperoleh pasutri yang mengikuti TRB pada kelompok usia $\leq 35$ tahun tingkat keberhasilan kehamilannya paling besar $(39,28 \%)$ dan tingkat keguguran yang kecil $(18,18 \%)$ dibandingkan kelompok usia $>35-40$ tahun dan 
kelompok usia $>40$ tahun. Ini memberikan gambaran bahwa dengan kualitas sel telur dan hormon reproduksi jenis steroid yang masih baik maka tingkat keberhasilan kehamilan semakin tinggi dan risiko terjadinya keguguran menjadi semakin kecil.

Disimpulkan bahwa tingkat keberhasilan pasutri yang mengikuti program TRB secara keseluruhan tingkat keberhasilannya 29,46\% (hamil klinis/ET). Tidak seperti yang banyak diinginkan para pasutri bahwa dengan TRB maka tingkat keberhasilannya akan tinggi, bahkan dipastikan akan mendapatkan kehamilan. Tingkat keberhasilan ini cukup tinggi, mengingt pada kondisi ini akan diperoleh keberhasilan nol apabila tidak dilakukan pertolongan dengan TRB. Tingkat keberhasilan kehamilan pada TRB banyak dipengaruhi oleh beberapa faktor yang tidak semua pasutri memahami, seperti : kualitas sperma, adanya kista ovarium, tumor jinak rahim (miom), keseimbangan hormon reproduksi, sampai usia pasutri terutama istri.

Dari data yang telah didapat terlihat bahwa salah satu penyebab gagalnya TRB adalah usia istri dan ini terlihat dari hasil pengamatan bahwa semakin tinggi usia istri keberhasilan kehamilan semakin menurun. Pada kelompok usia $\leq 35$ tahun tingkat keberhasilan kehamilan cukup tinggi yaitu 39,28\%, dibandingkan dengan kelompok usia > 35-40 tahun yaitu 27,86\% dan kelompok usia $>40$ tahun yang hanya 21,73\%. Keberhasilan kehamilan ini diikuti pula dengan terjadinya keguguran yang semakin meningkat pada usia $>40$ tahun sebesar $60 \%$, dibandingkan dengan usia $>35-40$ tahun sebesar $23,52 \%$ dan pada usia yang lebih muda $\leq 35$ tahun hanya sebesar $18,18 \%$.

Jadi dapat disarankan bagi pasutri yang telah melewati usia pernikahan 1 tahun tanpa kontrasepsi dengan hubungan suami-istri secara teratur dan belum mempunyai anak untuk segera memeriksakan diri ke dokter kandungan, agar penanganannya tidak terlambat. Sedangkan pasutri yang menikah dengan usia istri sudah melewati 35 tahun harus segera memeriksakan diri ke dokter kandungan karena mulai terjadi penurunan kualitas sel telur dan penurunan tingkat keberhasilan kehamilan pada teknik reproduksi berbantu.

\section{UCAPAN TERIMA KASIH}

Ucapan terima kasih kami sampaikan kepada tim TRB Aster, RS Hasan Sadikin, Bandung; Halim Fertility Center, Medan; Morula, RS Bunda, Jakarta; Melati, RSAB Harapan Kita Jakarta; Teratai, RS Gading Pluit Jakarta, Yasmin, Makmal/RSCM; Family, RS Family Pluit Jakarta Barat; Graha Amerta, RSSardjito Yogyakarta.

\section{DAFTAR PUSTAKA}

1. Piette C, de Mouzon J, Bachelot A, Spira A 1990 In-vitro fertilization: influence of women's age on pregnancy rates. Hum Reprod 5:56-59

2. Tucker MJ, Morton PC, Wright G, Ingargiola PE, Jones AE, Sweitzer CL 1995 Factors affecting success with intracytoplasmic sperm injection. Reprod Fertil Dev 7:229-236

3. Ashkenazi J, Orvieto R, Gold-Deutch R, Feldberg D, Dicker D, Voliovitch I, Ben Rafael Z 1996 The impact of woman's age and sperm parameters on fertilization rates in IVF cycles. Eur J Obstet Gynecol Reprod Biol 66:155-159

4. Hull MG, Fleming CF, Hughes AO, McDermott A 1996 The agerelated decline in female fecundity: a quantitative controlled study of implanting capacity and survival of individual embryos after in vitro fertilization. Fertil Steril 65:783-790

5. Widra EA, Gindoff PR, Smotrich DB, Stillman RJ 1996 Achieving multiple-order embryo transfer identifies women over 40 years of age with improved in vitro fertilization outcome. FertilSteril 65:103-108

6. Templeton A, Morris JK, Parslow W 1996 Factors that affect outcome of in-vitro fertilisation treatment. Lancet 348:1402-1406

7. Legro RS, Shackleford DP, Moessner JM, Gnatuk CL, Dodson WC 1997 ART in women 40 and over. Is the cost worth it? J Reprod Med 42:76-82

8. te Velde ER, Pearson PL 2002 The variability of female reproductive ageing. Hum Reprod Update 8:141-154

9. van Hooff MH, Alberda AT, Huisman GJ, Zeilmaker GH, Leerentveld RA 1993 Doubling the human menopausal gonadotrophin dose in the course of an in-vitro fertilization treatment cycle in low responders: a randomized study. Hum Reprod 8:369-373

10. Tarlatzis BC, Zepiridis L, Grimbizis G, Bontis J 2003 Clinical management of low ovarian response to stimulation for IVF: a systematic review. Hum Reprod Update 9:61-76

11. Faber BM, Mayer J, Cox B, Jones D, Toner JP, Oehninger S, Muasher SJ 1998 Cessation of gonadotropin-releasing hormone agonist therapy combined with high-dose gonadotropin stimulation yields favorable pregnancy results in low responders. FertilSteril 69:826-830

12. Muchsin J, Yuslam EF, Hadi S, Muharam, Soegiharto S: 20 tahun Pengalaman Pelayanan Program Bayi Tabung di Indonesia: Memperingati 20 tahun Program Bayi Tabung di Indonesia. Seminar Awam Perkembangan Mutakhir Penanganan Medis Masalah Ingin Anak. Jakarta, Mei 2008 